\title{
Development and Validation of the Measure of Initial Attraction - Short Interest Scale (MIA-I)
}

\author{
Desenvolvimento e Validação da Medida \\ de Atração Inicial - Escala Breve de Interesse (MIA-I) \\ David Rodrigues* \& Diniz Lopes \\ Instituto Universitário de Lisboa (ISCTE-IUL), CIS-IUL, Lisboa, Portugal
}

\begin{abstract}
Unilateral initial attraction (UIA) is a positive affective reaction following a unilateral perception of an unknown target, defining the first stage in developing a new interpersonal relationship. Although little attention is given to this construct, literature suggests it has a physiological activation component as well as an interpersonal interest component. However, this interest component emerges as necessary to willingly approach another person and eventually initiate interaction. Based on these evidences, we developed and validated the Measure of Initial Attraction - Interest Short Scale (MIA-I) in a sample of Portuguese-speaking individuals (Study 1, $N=544$ ). Results suggest the MIA-I is a valid and reliable instrument (Study 1; Study 2a), and show its capacity to discriminate UIA across different relationships (Study 1) and to differentiate UIA from passion and love (Study 1). Towards an unknown target, the MIA-I also distinguished UIA from liking (Study 2b). These results show that the MIA-I assesses a specific construct, differentiated from liking, passion and love, and suggest its importance to understand the UIA phenomenon.

Keywords: Unilateral initial attraction (UIA), Measure of Initial Attraction, construct validity, convergent validity.
\end{abstract}

\begin{abstract}
Resumo
Atração inicial unilateral (UIA) é uma reação afetiva positiva após a percepção unilateral de um alvo desconhecido, definindo o primeiro estádio no desenvolvimento de um novo relacionamento interpessoal. Apesar de pouco estudado, a literatura sugere este constructo como tendo uma componente de ativação fisiológica e outra de interesse interpessoal. Contudo, a componente de interesse emerge como necessária para uma aproximação voluntária a outra pessoa e eventual iniciação de uma interação. Com base nestas evidências, desenvolvemos e validámos a Medida de Atração Inicial - Escala Breve de Interesse (MIA-I) numa amostra de indivíduos de língua Portuguesa (Estudo 1, $N=544$ ). Os resultados sugerem o MIA-I como um instrumento válido e com níveis adequados de consistência interna (Estudo 1; Estudo 2a) e mostram a sua capacidade para discriminar UIA entre diferentes relacionamentos (Estudo 1) e para distinguir UIA de paixão e amor (Estudo 1). Para um alvo desconhecido, o MIA-I permitiu ainda distinguir UIA de gostar (Estudo 2b). Estes resultados mostram que o MIA-I acede a um constructo específico e diferenciado de gostar, paixão e amor, sugerindo a sua importância para a compreensão do fenómeno de atração inicial unilateral.

Palavras-chave: Atração Inicial Unilateral, Medida de Atração Inicial, validade de constructo, validade convergente.
\end{abstract}

Sometimes we glance over at a stranger and experience a sudden urge in wanting to know more about him/her. Given the proper initial conditions (e.g., reciprocity), this can lead to an interaction, which, depending on

* Mailing address: Instituto Universitário de Lisboa (ISCTE-IUL), Centro de Investigação e Intervenção Social, Av. das Forças Armadas, Lisboa, Portugal 1649026. E-mail: dflrs@iscte.pt

Research funded by Fundação para a Ciência e a Tecnologia (SFRH/BD/21337/2005; SFRH/BPD/73528/2010). We thank Teresa Garcia-Marques for her comments on a previous draft of this article, and Anabela Ventura, Carolina Santos, Jamie Lopes, and Sandra Correia for their help in collecting the data other conditions (e.g., common interests), can lead to the development of a relationship (Miller, Perlman, \& Brehm, 2007). Classical views on attraction define it as a positive attitude towards another person (Berscheid \& Walster, 1978; Hendrick \& Hendrick, 1992) and stress the importance of factors such as previous knowledge about the person (e.g., Montoya, Horton, \& Kirchener, 2008) or occurrence of pleasant interactions (e.g., Finkel \& Eastwick, 2008). According to these views, then, the exchange of (positive) information would determine the experience of attraction and the initiation of a new relationship (Kerckhoff \& Davis, 1962; Knapp, 1984; Lewis, 1972; Reiss, 1960; Scanzoni, 1979). 
However, in certain situations an individual can experience attraction immediately after a first unilateral awareness of another person, prior to reciprocal awareness, interpersonal contact (e.g., glancing at each other; "love at first sight"), or interpersonal interaction (e.g., engaging in conversation). This defines unilateral initial attraction (UIA; Rodrigues \& Lopes, 2014), conceptualized as the necessary first stage to initiate a new relationship (Rodrigues, 2010). Indeed, and as Levinger and Snoek (1972) point out, "the beginnings of a relationship appear when one person (P) becomes aware of another (O)", and "it is unimportant whether or not $\mathrm{O}$ in turn notices $\mathrm{P}$. The only pertinent event is that $\mathrm{P}$ has information that forms a basis for his unilateral evaluation of O" (p. 6). In other words, if the unilateral awareness of the target is not followed by a positive first reaction (i.e., UIA), then no interest in wanting to find out more about the target emerges, no first voluntary interaction occurs, and no interpersonal relationship follows (Bredow, Cate, \& Huston, 2008; Levinger, 1974; Murstein, 1970; see also Afifi \& Lucas, 2008; Berscheid \& Regan, 2005; Cunningham \& Barbee, 2008; Sprecher \& Felmlee, 2008). This is the focus of our present investigation.

Previous research conducted by Rodrigues and Lopes (2014) shows UIA as a valid, socially shared, and relevant construct. To properly conduct research within the UIA phenomenon and analyze its influence in determining the initiation of voluntary relationships, it was necessary to develop a new measurement instrument. The authors developed and validated the Measure of Initial Attraction (MIA), a valid and reliable instrument with the capacity to differentiate UIA across targets and types of relationships (Rodrigues \& Lopes, 2014). Even though the MIA comprises a component of physiological arousal and a component of interpersonal interest, results give primacy to the interest component to determine the experience of UIA across relationships. Specifically, while individuals reported more interest towards a UIA target when compared to a love target, a friend or a colleague, the arousal component did not differentiate the UIA and love targets. In other words, while arousal seems to be shared (at last sometimes) with other romantic and sexual relationships (e.g., love, which has a component of sexual desire; Hatfield, Bensman, \& Rapson, 2012; Moser, 1994), interest seems to be determinant to initiate a new relationship and to keep the interest in maintaining different types of relationships (e.g., love, friendships, colleagues).

Bearing these evidences in mind, the present article seeks to extend these results and present a new measurement instrument. Even though the arousal component is an important aspect of UIA, it is not a necessary condition given that not all interpersonal relationships are grounded in the experience of sexual attraction or desire (Moser, 1994). The interest component, on the other hand, is the essential characteristic that defines the experience of UIA. As such, we focus on this component and develop the Measure of Initial Attraction - Interest Short Scale (MIA-I). In doing so, we propose a more specific measure that can be broadly used to study the initiation of any type of relationship, without the arousal component that only characterizes sexually-based relationships (e.g., sexual encounters, passion, love). More specifically, in this article we present MIA-I's validity and reliability evidence enabling a more objective and reliable measurement of UIA.

\section{MIA-I Development}

UIA is a positive affective reaction promoted on a first unilateral perception of another person, in a situation where no objective information is available (Rodrigues, 2010). Literature suggests UIA as the first step to initiate voluntary relationships (e.g., Bredow et al., 2008), mainly determined by interpersonal interest when unilaterally perceiving another person (Rodrigues \& Lopes, 2014). As relationships vary along the dimensions of affection and sexual desire (Moser, 1994), interpersonal interest is a common link across different types of relationships (e.g., friendship, love), and therefore its measurement is determinant to reliably assess UIA.

The MIA (cf. Rodrigues \& Lopes, 2014) was recently proposed as a valid and reliable scale to access the UIA construct. This is defined by three characteristics: (a) positivity and affection towards another person; (b) personal interest and willingness to interact; and (c) physiological arousal. The first two characteristics suggest UIA as a first step to initiate and develop different types of relationships. However, and due to the unilateral nature of the UIA, the third characteristic is assumed to emerge mostly at a fantasy level (contrary to constructs such as falling/being in love; e.g., Regan, Kocan, \& Whitlock, 1998). In its final format, MIA is a bi-factorial scale, with 16 items concerning arousal and covering physiological aspects of UIA, and 12 items concerning interest and covering positivity, affect and interpersonal interest aspects.

Assuming that interpersonal relationships (e.g., love vs. friendship) share some attributes (e.g., affection) and differentiate others (e.g., desire), it is reasonable to think similarly regarding the UIA. Furthermore, given that interpersonal interest underlies all types of interpersonal relationships thus leading to voluntary interpersonal approach (unlike arousal, which does not characterize all types of relationships), we propose a new measure that allows researchers to assess UIA more rapidly and more efficiently. To do so, we focus on the original 12 MIA's interest items, and reanalizing Rodrigues and Lopes' (2014) Study 2 data we compared mean scores in each item across the UIA, love, friendship and colleague targets. We thus ensure the identification of the overlapped/shared attributes, and the differentiated/exclusive attributes, in characterizing the UIA experience (Table 1). 
Rodrigues, D. \& Lopes, D. (2015). Development and Validation of the Measure of Initial Attraction - Short Interest Scale (MIA-I).

Table 1

Comparison between MIA-I's Eligible Items, according to the Target

\begin{tabular}{llcccc}
\hline & & \multicolumn{3}{c}{ Target } \\
\cline { 2 - 6 } & Attributes & UIA & Love & Friendship & Colleague \\
Shared & Affection & $M(S D)$ & $M(S D)$ & $M(S D)$ & $M(S D)$ \\
\hline & Empathy & $5.14(1.55)$ & $4.67(1.93)$ & $4.91(1.43)$ & $4.16(1.75)^{*}$ \\
& Joy & $5.49(1.46)$ & $5.02(1.60)$ & $5.07(1.55)$ & $4.61(1.77)^{*}$ \\
& Keen to please & $5.74(1.30)$ & $5.14(1.53)^{*}$ & $5.46(1.41)$ & $4.36(1.72)^{*}$ \\
& Willingness to laugh with & $5.55(1.06)$ & $5.14(1.51)$ & $4.84(1.42)^{*}$ & $4.26(1.56)^{*}$ \\
& Reciprocity of feelings & $5.90(1.19)$ & $5.09(1.71)^{*}$ & $5.45(1.37)$ & $4.47(1.71)^{*}$ \\
attributes & $4.77(1.62)$ & $4.95(1.62)$ & $4.54(1.60)$ & $3.79(1.70)^{*}$ \\
& Curiosity & $5.98(.98)$ & $4.90(1.49)^{*}$ & $4.82(1.59)^{*}$ & $4.37(1.65)^{*}$ \\
& Pleasant & $5.79(1.02)$ & $5.11(1.47)^{*}$ & $5.27(1.35)^{* *}$ & $4.66(1.58)^{*}$ \\
& Willingness to be with & $5.77(1.24)$ & $5.11(1.63)^{*}$ & $4.90(1.55)^{*}$ & $4.21(1.70)^{*}$ \\
& Willingness to exchange smiles & $5.72(1.43)$ & $5.07(1.74)^{*}$ & $4.66(1.70)^{*}$ & $4.13(1.70)^{*}$ \\
& Willingness to know & $6.37(.80)$ & $5.38(1.48)^{*}$ & $5.10(1.70)^{*}$ & $4.69(1.74)^{*}$ \\
& Willingness to spend time with & $6.17(.98)$ & $5.52(1.51)^{*}$ & $5.18(1.36)^{*}$ & $4.28(1.79)^{*}$ \\
\hline
\end{tabular}

Note. Data originally from Rodrigues and Lopes' (2014) Study 2. $N=374$ (62.6\% females). None of these analyses were carried in the original study. UIA = Unilateral initial attraction.

*Significantly different from UIA scores (post-hoc Tukey comparison, $p<.05$ ).

**Significantly different from UIA scores (post-hoc Tukey comparison, $p=.06$ ).

Table 2

Centrality Indexes for MIA-I's Eligible Items

\begin{tabular}{llcccc}
\hline & & Phase 1 & Phase 2 & \\
\cline { 2 - 6 } Shared & Attributes & Frequency & Characteristic & Mandatory & Important \\
attributes & Affection & 1.6 & 4.39 & 56.7 & 16.3 \\
& Empathy* & 12.1 & 5.08 & 83.3 & 22.4 \\
& Joy* & 20.2 & 5.70 & 89.8 & 23.5 \\
& Keen to please & 2.4 & 4.81 & 61.9 & 9.2 \\
& Willingness to laugh with* & 3.2 & 5.34 & 76.0 & 22.4 \\
& Reciprocity of feelings & 4.0 & 5.36 & 76.5 & 18.4 \\
Exclusive & Curiosity & 3.2 & 5.16 & 78.1 & 19.4 \\
& Pleasant & 2.4 & 5.54 & 89.8 & 5.1 \\
& Willingness to be with* & 14.5 & 6.01 & 92.7 & 38.8 \\
& Willingness to exchange smiles & 12.9 & 5.86 & 90.7 & 48.5 \\
& Willingness to know* & 16.1 & 5.47 & 87.6 & 34.7 \\
& Willingness to spend time with & 9.7 & 5.70 & 89.7 & 30.9 \\
\hline
\end{tabular}

Note. Data originally from Rodrigues and Lopes' (2014) Study 1. Phase 1, $N=124$ (70.2\% females); Phase 2, $N=98$ (73.5\% females). Frequency refers to the percentage of participants who spontaneously indicated the attribute as characteristic of initial attraction; characteristic refers to the average of perceived attribute centrality on a seven-point scale; mandatory refers to the percentage of participants who considered the attribute as mandatory for the experience of initial attraction (Yes responses); and important refers to the percentage of participants who indicated the attribute as one of the ten most important to experience initial attraction. This is a summary of the original data presented by the author's in which to base the selection of attributes for the MIA-I. Attributes chosen for the MIA-I are marked with an asterisk $(*)$. 
Results converge with the notion of UIA as having shared and exclusive attributes, underlying different relationships. Table 1 reveals six shared attributes (whose mean scores on the UIA target were not different from, at least, one of the remaining targets) and six exclusive attributes (whose mean scores on the UIA target were different from the remaining targets).

As interest emerges as determinant to UIA (Rodrigues \& Lopes, 2014), we reasoned the importance of both types of attributes when developing a short scale. Hence, we relied on Rodrigues and Lopes' (2014) Study 1 data regarding the attributes' centrality scores for the UIA construct (Table 2), to select the final attributes for the MIA-I.

We selected the five most central attributes to UIA's interest. Three of these referred to shared attributes, and two referred to exclusive attributes. Following this, we analyzed MIA-I's construct validity, convergent validity and reliability.

\section{Study 1}

The first study sought to validate the MIA-I. Also, it aimed at studying the measure's capacity to discriminate UIA's interest across relationships. Although UIA is assumed as underlying different relationships, its subjective experience is distinct (Rodrigues \& Lopes, 2014). Hence, we also expect MIA-I to prove more sensitive in measuring UIA for an unknown other (UIA target), than for a one's passion partner, romantic partner, a friend or a work colleague.

\section{Method}

\section{Participants and Design}

A total of 544 individuals $\left(64.3 \%\right.$ females; $M_{\mathrm{Age}}$ $=21.55, S D=2.90$ ) took part in this study, randomly assigned to one of five conditions: (a) UIA target ( $n=$ 136), (b) passion target $(n=86)$, (c) love target $(n=74)$, (d) friendship target $(n=107)$, or (e) colleague target $(n=$ 141). Across the five conditions, participants did not differ in regards to mean age, $F<1($ Min. $=21.25$, Max. $=21.71)$, and to female/male ratio, $\chi^{2}(4, N=544)=4.17, p=.384$.

\section{Procedure and Measures}

Individuals were randomly approached by the researchers and invited to participate in a study about interpersonal relationships. Upon consent, they were randomly handed a booklet for completion. The first page asked them to indicate their age and gender, and to either think about "a person for whom you felt an immediate attraction when seeing him/her for the first time" (UIA target), "the person for whom you currently feel passion" (passion target), "the person with whom you have a romantic relationship" (love target), "a close friend for whom you do not feel attraction, passion, or love" (friendship target), or "a work colleague that you like but for whom you do not feel attraction, passion, or love" (colleague target).
While thinking about the target, participants were asked to complete the MIA-I, the Passionate Love Scale (PLS; $\alpha=.91$; Hatfield \& Sprecher, 1986), and the Eros scale $(\alpha=.77$; Hendrick, Hendrick, \& Dicke, 1998). The dependent measures were presented in random order within conditions. Responses were given in 7-point scales $(1=$ Not at all to $7=A$ lot $)$. In specific target conditions, participants were then presented with control questions. For the UIA target, participants were asked if they personally knew ( $\mathrm{Yes} / \mathrm{No}$ ) and had previously interacted with the person $(\mathrm{Yes} / \mathrm{No})$, while for both passion and love targets, participants were asked to characterize their feeling in intensity $(1=$ Low intensity, $7=$ High intensity $)$ and involvement $(1=$ Low involvement, $7=$ High involvement). After completion, participants were debriefed and thanked.

\section{Results and Discussion}

\section{Confirmatory Factor Analysis (CFA)}

We ran two CFA and obtained fit indexes of a unifactorial model (hypothesized model), and a two-correlated factors model testing the possibility of exclusive and shared attributes loading in distinct, but correlated, factors. CFA analyses were conducted using M-plus (Muthén \& Muthén, 2010), and both relative and absolute goodness of fit indexes were obtained: (a) chi-squared statistic, (b) comparative fit index (CFI), (c) Tucker-Lewis Index (TLI), (d) root mean square error of approximation (RMSEA), and (e) standardized root mean squared residual (SMSR). Models were estimated using maximum likelihood estimation with the Yuan-Bentler correction for skewness (MLR; Muthén \& Muthén, 2010).

Based on fit indexes standards (Bentler, 1990; Browne \& Cudeck, 1989; Jöreskog \& Sörbom, 1984), our hypothesized model showed an acceptable fit, $\chi^{2}=23.44$, $\chi^{2} / d f=4.69, \mathrm{CFI}=.99, \mathrm{TLI}=.97, \mathrm{RMSEA}=.08(\mathrm{CI}: .05$; .12 ) and SRMR $=.01$, with high standardized regression paths between the items and their latent construct $\left(\lambda_{\mathrm{s}}\right.$ from .88 to .96$)$. The alternative model presented poorer fit indexes, $\chi^{2}=14.26, \chi^{2} / d f=3.56, \mathrm{CFI}=.93$, TLI $=.84$, RMSEA $=.17$ (CI: .08; .28) and SRMR $=.03$.

\section{Reliability and Sensitivity Analysis}

Given the high levels of internal consistency of the MIA-I (Cronbach's $\alpha=.97$; corrected item-total correlations $r>.88$ ), we computed an overall mean score. For the total sample, mean MIA-I scores were significantly above the mid-point of the 7-point response scale $(M=4.79$, $S D=2.01), t(543)=9.09, p<.001, d=.78($ Minimum $=$ 1.00 , Maximum $=7.00)$, with a platykurtic $($ kurtosis $/$ std. error $=-4.93$ ) and negatively skewed (skewness/std. error $=-5.88$ ) distribution. We found similar results for the UIA target, with MIA-I mean scores significantly above the mid-point of the 7-point response scale $(M=5.72, S D$ $=1.15), t(135)=17.45, p<.001, d=3.00($ Minimum $=$ 1.00 , Maximum $=7.00)$, with a leptokurtic $($ kurtosis/std. 
Rodrigues, D. \& Lopes, D. (2015). Development and Validation of the Measure of Initial Attraction - Short Interest Scale (MIA-I).

error $=6.52)$ and negatively skewed (skewness/std. error $=-6.78$ ) distribution.

\section{Convergent Validity}

To test MIA-I's capacity to distinguish UIA from passion and passionate love, we analyzed participants' mean scores on each measure. Considering the five targets
(UIA, passion, love, friendship, and colleague), an ANOVA analysis reveals a main effect for MIA-I, F $(4,539)$ $=207.51, p<.001, \eta_{p}{ }^{2}=.61$, PLS, $F(4,539)=301.01, p$ $<.001, \eta_{p}{ }^{2}=.69$, and Eros scores, $F(4,539)=232.61, p$ $<.001, \eta_{p}{ }^{2}=.63$. To better understand these differences, we compared mean scores within each target (see Table 3 for mean scores).

Table 3

Scores for Each Target on the MIA-I, PLS and Eros Measures (Study 1)

\begin{tabular}{lccccc}
\hline & \multicolumn{5}{c}{ Target } \\
\cline { 2 - 6 } & Initial attraction & Passion & Love & Friendship & Co-worker \\
\cline { 2 - 6 } & $M(S D)$ & $M(S D)$ & $M(S D)$ & $M(S D)$ & $M(S D)$ \\
\hline MIA-I & $5.72(1.15)$ & $6.32(.72)$ & $6.36(.82)$ & $4.45(1.72)$ & $2.37(1.42)$ \\
PLS & $4.86(1.23)$ & $5.64(.86)$ & $5.72(.96)$ & $2.39(1.14)$ & $1.77(1.21)$ \\
Eros & $4.68(1.30)$ & $5.70(1.06)$ & $5.71(1.06)$ & $3.12(1.16)$ & $1.91(1.08)$ \\
\hline
\end{tabular}

Planned contrasts on the UIA target reveal higher MIA-I scores $(M=5.72, S D=1.15)$ when compared to the combined PLS/Eros scores, $t(539)=11.98, p<.001$, $d=1.03$. This supports MIA-I as valid, distinguishing UIA from passion and passionate love.

Planned contrasts show no differences between PLS and Eros scores either for the passion target $(M=5.64 v s$. $M=5.70$, respectively) or the love target ( $M=5.72 \mathrm{vs}$. $M=5.71$, respectively), both $t<1$. This is not surprising as passion and love feelings were characterized by high intensity $(M=6.17, S D=.98 ; M=6.11, S D=1.14$, respectively) and involvement ( $M=6.01, S D=1.21 ; M=6.15$, $S D=1.06$, respectively). Although we expected higher PLS and Eros (vs. MIA-I) scores for the passion and love targets, our data showed otherwise. Planned contrasts on the passion target show higher MIA-I scores $(M=6.32, S D$ $=.72$ ) when compared to the combined PLS/Eros scores, $t(539)=6.51, p<.001, d=.56$, and similarly planned contrasts on the love target also show higher MIA-I scores ( $M=6.36, S D=.82)$ when compared to the combined PLS/ Eros scores, $t(538)=6.02, p<.001, d=.52$.

This could raise validity issues, suggesting MIA-I as a more sensible measure of passion or love. However, note that PLS and Eros assesses other aspects such as commitment, sexuality or fear of relationship. Assuming UIA to underlie all voluntary relationships, then we argue that, apart from these additional aspects, as one gets to know more and experience positive interactions with the romantic partner, more interest arises in deepening the relationship, resulting in higher MIA-I scores (vs. PLS/Eros).

Further supporting the MIA-I's validity are the results for the friendship and colleague targets. Planned contrasts on the friendship target show higher MIA-I scores $(M=$ $4.45, S D=1.72$ ) when compared to the combined PLS/ Eros scores, $t(538)=19.03, p<.001, d=1.64$, and simi- larly planned contrasts on the colleague target show higher MIA-I scores $(M=M=2.37, S D=1.42)$ when compared to the combined PLS/Eros scores, $t(538)=6.91, p<.001$, $d=.60$. These evidences suggest that MIA-I tapped a facet of friendship and liking that neither PLS or Eros measured. Planned contrasts also show higher MIA-I scores on the friendship ( $v s$. colleague) target, $t(539)=12.79, p<.001$, $d=1.10$, thus showing the distinction of interest associated with each target and effectively assessed by MIA-I.

These results suggest MIA-I as an objective and valid instrument for measuring UIA's interest in wanting to know an unknown person, pointed as necessary and determinant component of such subjective experience (Rodrigues \& Lopes, 2014). Composed by shared and exclusive attributes, MIA-I was also shown to reliably assess and differentiate UIA's interest across different relationships. However, we must acknowledge that we did not directly address UIA's conceptualization. Indeed, although participants were asked to think about a person for whom they felt an immediate attraction after seeing him/her for the first time, most indicated to personally know (94.1\%) and to have previously interacted $(97.0 \%)$ with such target. This converges with the notion that people tend to consider close others when asked to think of a person (Fehr $\&$ Sprecher, 2009). Hence, in the second study we aimed at validating the MIA-I in a context devoid of objective information or knowledge about the other person (Study 2a), and also study UIA's differentiation from liking (Study $2 b)$. The theoretical importance of these two studies relies in the fact that they will allow us to validate the MIA-I in a more specific and controlled laboratory setting, closely resembling the conceptualization of UIA and controlling for additional target related variables (e.g., clothing style) that can impact perception and impression formation and influence attraction. 


\section{Study 2}

The purpose of this study was twofold. In Study 2 a we sought to validate MIA-I in a situation where individuals perceive an unknown person, neutral in attractiveness, without additional information being provided. This directly addresses UIA's conceptualization, allowing us to control not only the previous knowledge associated to the target (given that in Study 1 most participants thought of a known target), but also the impact of external variables (e.g., clothing) known to influence target judgment in unexpected ways (e.g., Albright, Kenny, \& Malloy, 1988).

In Study $2 \mathrm{~b}$ we analyzed MIA-I's ability to disentangle UIA and liking. In defining attraction as a predisposition to positively evaluate another person (Hendrick \& Hendrick, 1992), literature tends do rely on liking as a proxy (e.g., Rubin, 1970). However, liking can assume different meanings (Graziano \& Bruce, 2008), namely empathy, respect or trust in the person's social/working skills (e.g., Rubin, 1970), or satisfaction, friendship, or love (e.g., Sternberg, 1986). Hence, we argue that liking does not necessarily promote a voluntary willingness to approach, want to know or even interact with another person.

One possible way of empirically demonstrating this is through the derogation phenomenon. According to the Investment Model (Rusbult, 1980, 1983), committed individuals tend to activate a set of relationship-protection behaviors when perceiving a potential threat (see Rusbult \& Righetti, 2009). We focus on derogation, whereby committed (vs. single) individuals report less attraction towards an attractive target (e.g., Simpson, Gangestad, \& Lerma, 1990).

As UIA reflects interest, such positive reaction among committed individuals may signal a potential threat to the relationship stability, thus leading to derogation. On the other hand, as liking reflects empathy/respect, it may not trigger the perception of threat among committed individuals. Hence, we expect committed ( $v$ s. single) individuals to report less UIA, while not expecting no differences in liking between committed and single participants.

\section{Method}

\section{Participants}

Study 2a: 85 heterosexual female undergraduates took $\operatorname{part}\left(M_{\text {Age }}=20.39, S D=2.85\right)$.

Study $2 b: 29$ heterosexual female undergraduates took $\operatorname{part}\left(M_{\mathrm{Age}}=19.55, S D=3.04\right)$. From these, $58.6 \%$ were in a romantic relationship $\left(M_{\text {Duration }}=16.24\right.$ months, $S D$ $=12.42)$, characterized as serious $(M=8.00, S D=1.28$, where $1=$ Occasional and $9=$ Serious) with high level of involvement $(M=8.18, S D=.88$, where $1=$ Low involvement and $9=$ High involvement $)$.

\section{Procedure and Measures}

In both studies participants voluntarily took part in exchange for course credits. Upon arrival to the labora- tory, participants were asked to take a seat in front of a computer. After reading the instructions, participants were randomly presented with the target's photo. This was a $3 \times 4$ inches grey-scale headshot of a male, neutral in attractiveness $(\mathrm{M}=4.70, \mathrm{SD}=1.73$, where $1=$ Ugly and 9 = Beautiful; see Rodrigues, 2010). The presentation of the target was followed by the dependent measures. In Study 2a participants saw the five items of the MIA-I $(\alpha=.97$; e.g., If I came to know this person, I would feel joy). In Study $2 \mathrm{~b}$ participants saw the MIA-I and the two items of the Interpersonal Judgment Scale (IJS; split-half $\alpha=.85$; Byrne, 1971). These measures were presented in random order. In both studies judgments were given on nine-point scales $(1=$ Not at all, $9=A$ lot $)$. After this, participants were asked to provide biographic information (e.g., age), and at the end they were debriefed and thanked.

\section{Results and Discussion}

\section{Study 2a: Reliability and Sensitivity Analysis}

MIA-I items presented a high internal consistency ( $\alpha$ $=.93$ ) with high item-total correlations $(r>.76)$. Mean MIA-I scores were significantly below the mid-point of the 9-point response scale $(M=3.95, S D=2.02), t(84)$ $=-4.78, p<.001, d=-1.04$ (Minimum $=1.00$, Maximum $=8.40$ ), with an approximately normal distribution (kurtosis/std. error $=-2.19 ;$ skewness/std. error $=1.01)$. These results validate the MIA-I in this specific setting, in which participants were presented with the headshot of an unknown target, neutral in attractiveness and void of additional information.

\section{Study 2b: MIA-I, IJS and Derogation}

Both IJS items were highly correlated $(r=.66, p<$ $.001)$. Mean scores were significantly below the mid-point of the 9-point response scale $(M=3.76, S D=1.26), t(28)$ $=-5.21, p<.001, d=-1.97$ (Minimum $=1.00$, Maximum $=6.00$ ), with a normal distribution (kurtosis/std. error $=$ $-.91 ;$ skewness $/$ std. error $=-1.00$ ) .

Recall that we expected evidences of derogation in MIA-I, but not in IJS, scores. As expected, an ANOVA analysis revealed lower MIA-I scores among committed $(M=3.22, S D=1.23)$, compared to single $(M=4.12, S D$ $=.78)$, participants, $F(1,27)=4.90, p=.04, \eta_{p}{ }^{2}=.15$. No differences emerged for IJS scores, $F<1$, between committed $(M=3.71, S D=1.24)$ and single $(M=3.88, S D=$ 1.35) participants.

Again, these results support MIA-I as a valid and reliable measure. Importantly, results also support the distinction between UIA and liking, showing that romantically committed individuals ( $v$ s. single individuals), reported less UIA, while no differences emerged for liking. Hence, UIA seems to be a specific type of interpersonal interest that can lead to the development of a relationship (thus leading to derogation) that goes beyond liking, empathy and/or respect (not leading to derogation). 
Rodrigues, D. \& Lopes, D. (2015). Development and Validation of the Measure of Initial Attraction - Short Interest Scale (MIA-I).

\section{General Discussion}

The studies herein presented seek to generate a new, valid and reliable means of measuring UIA, conceptualized as a positive reaction after first becoming aware of an unknown other in the absence of additional objective information (Rodrigues, 2010). Although classical views on attraction tend to overlook the UIA phenomenon and focus on variables associated to romantic and/or sexual attraction (e.g., attractiveness; Buss \& Barnes, 1986), empirical evidences suggest interpersonal interest to be determinant when experiencing UIA (Rodrigues \& Lopes, 2014). This follows directly the argument that UIA is the first necessary stage to initiate/develop relationships (Bredow et al., 2008), some of which not characterized by sexual desire (e.g., friendships; Moser, 1994), and thus our research is an important first step to the understanding of such important phenomenon for relationship initiation.

We reanalyzed Rodrigues and Lopes' (2014) original data and proposed shorter version of the MIA's interest component. The MIA-I comprises five attributes, three shared with, and two exclusive from, feelings of love and/ or friendship. Study 1 showed MIA-I to have a unifactorial structure with high reliability, validity in assessing UIA across relationships, and capacity to differentiate UIA from passion and love. We found higher MIA-I scores for the passion and love targets (vs. PLS/Eros scores) and even though this could be indicative of greater sensitivity in measuring such feelings, we argue otherwise. While MIA-I assessed interpersonal interest for these targets, PLS and Eros assessed additional factors in the relationships such as commitment, sexuality or fear of rejection. Not considering this, it is not surprising that participants reported a high interest in wanting to know (even) more about their partner, reflecting higher MIA-I scores. Study 2 took the validation further, showing MIA-I's validity in a situation directly operationalizing UIA (Study 2a), and the distinction between UIA and liking (Study 2b).

Literature suggests that when no information is readily available to form an objective judgment (following Study 2 's procedure), individuals experience a higher level of ambiguity and uncertainty (e.g., Ambady, Bernieri, \& Richerson, 2000). Understanding this psychological mechanism should help us understand the UIA phenomenon and the variables that influence it. Indeed, recent investigation sheds some light on this and unveils perceived similarity as a mediator of the UIA phenomenon (cf. Rodrigues, Lopes, Alexopoulos, \& Goldenberg, 2014).

Besides this direct implication, our measure is of great importance to study other phenomena within committed romantic relationships. Results from Study $2 b$ show that individuals in a committed romantic relationship ( $v s$. single individuals) evidenced derogation in their MIA-I scores, while no differences emerged for the IJS. The reasoning behind these results is that UIA promotes interpersonal interest towards an unknown other, which can be perceived as a potential threat to the stability of the current romantic relationship. On the contrary, liking may signal general empathy or respect, not signalizing necessarily such interest in wanting to know more about the target. Rather than undermining the validity of our measure, these results may be indicative of a healthy relationship and support its applicability is these situations as an indicator of perceived quality of potential alternatives, which in turn is one of the predictors of commitment (Le \& Agnew, 2003).

We are dealing with a recent construct and more studies need to be undertaken in order to further analyse this construct, nonetheless, this new measure - MIA-I - emerges as a relevant, valid and reliable instrument that can help us understand a fundamental phenomenon in relationship initiation. Hence, the MIA-I has relevant applicability in academic and professional settings. On the one hand, academics have an important research tool to reliably assess UIA and study the UIA phenomenon from situations devoid of information about the target (zeroacquaintance), to situations where objective information is readily available to the individual (e.g., attitudinal views of the target), situations where the target is associated with availability (e.g., willingness to meet the individual) and/or reciprocity of interest, up to situations where the individual anticipates an interaction with the target. By examining the UIA phenomenon across these situations (either experimentally or longitudinally), using the MIA-I as one of the central measurement instruments, academics will be able to understand the variables that influence each stage in initiating and developing a new relationship. Taking our results, such understanding would be more accurate using the MIA-I, compared to proxy measures such as liking, sexual attraction, passionate love or romantic love, given the distinction of UIA and the constructs measured by those instruments.

On the other hand, results also show MIA-I's applicability in understanding commitment in romantic relationships. By assessing an interpersonal interest in another (alternative) person, both academics and professionals have a valuable tool to understand derogation and a stability protection mechanism. Given the distinctiveness of the UIA, again, this would be more accurate than with measures of liking (which did not activate derogation of the target) or more romantically- or sexually-based measures. In this latter case, such measures may always promote derogation given the nature of their questions, regardless of any type of manipulation associated with the target. For instance, in an experimental context where the target is associated reciprocal interest in developing a friendship based on similar interests, committed individuals may report higher interpersonal interest not perceiving threat to the stability of their relationship (MIA-I), while reporting low sexual interest in the target. This is valuable not only for academics to understand the UIA phenomenon and the derogation mechanism, but also for professionals to develop intervention programs, for instance in couple's 
counseling, to better the adjustment and quality of the romantic relationship.

To sum up, the studies presented in this article are a step forward in the analysis of UIA, and in the development of a valid and reliable instrument to measure the determinant component of such experience - interpersonal interest. This is in line with, and directly converges with the need pointed out by Rodrigues and Lopes (2014) of developing a shorter version of the original MIA, facilitating its application in experimental settings.

\section{References}

Afifi, W., \& Lucas, A. (2008). Information seeking in the initial stages of relationship development. In S. Sprecher, A. Wenzel, \& J. Harvey (Eds.), Handbook of relationship initiation (pp. 135-151). New York: Psychology Press.

Albright, L., Kenny, D., \& Malloy, T. (1988). Consensus in personality judgments at zero acquaintance. Journal of Personality and Social Psychology, 55, 387-395. doi:10.1037//00223514.55.3.387

Ambady, N., Bernieri, F., \& Richerson, J. (2000). Toward a histology of social behavior: Judgmental accuracy from thin slices of the behavioral stream. Advances of Experimental Social Psychology, 32, 201-271.

Bentler, P. (1990). Comparative fit indexes in structural models. Psychological Bulletin, 107, 238-246. doi:10.1037//00332909.107.2.238

Berscheid, E., \& Regan, P. (2005). The psychology of interpersonal relationships. Mahwah, NJ: Prentice Hall.

Berscheid, E., \& Walster, E. (1978). Interpersonal attraction $\left(2^{\text {nd }}\right.$ ed.). Reading, MA: Addison-Wesley.

Browne, M., \& Cudeck, R. (1989). Single sample cross-validation indices for covariance structures. Multivariate Behavioral Research, 24, 445-455. doi:10.1207/s15327906mbr2404_4

Bredow, C., Cate, R., \& Huston, T. (2008). Have we met before?: A conceptual model of first romantic encounters. In S. Sprecher, A. Wenzel, \& J. Harvey (Eds.), Handbook of relationship initiation (pp. 3-28). New York: Psychology Press.

Buss, D., \& Barnes, M. (1986). Preferences in human mate selection. Journal of Personality and Social Psychology, 50, 559-570. doi:10.1037//0022-3514.50.3.559

Byrne, D. (1971). The attraction paradigm. New York: Academic Press.

Cunningham, M., \& Barbee, A. (2008). Prelude to a kiss: Nonverbal flirting, opening gambits, and other communication dynamics in the initiation of romantic relationships. In S. Sprecher, A. Wenzel, \& J. Harvey (Eds.), Handbook of relationship initiation (pp. 97-120). New York: Psychology Press.

Fehr, B., \& Sprecher, S. (2009). Prototype analysis of the concept of compassionate love. Personal Relationships, 16, 343-364. doi:10.1111/j.1475-6811.2009.01227.x

Finkel, E. J., \& Eastwick, P. W. (2008). Speed-dating. Current Directions in Psychological Science, 17, 193-197. doi:10.1111/j.1467-8721.2008 .00573.x

Graziano, W., \& Bruce, J. (2008). Attraction and the initiation of relationships: A review of the empirical literature. In S. Sprecher, A. Wenzel, \& J. Harvey (Eds.), Handbook of relationship initiation (pp. 269-295). New York: Psychology Press.

Hatfield, E., Bensman, L., \& Rapson, R. (2012). Love and intimacy. In V. Ramachandran (Ed.), Encyclopedia of human behavior ( $2^{\text {nd }}$ ed., pp. 550-556). New York: Academic Press.
Hatfield, E., \& Sprecher, S. (1986). Measuring passionate love in intimate relationships. Journal of Adolescence, 9, 383-410. doi:10.1016/S0140-1971(86)80043-4

Hendrick, C., Hendrick, S., \& Dicke, A. (1998). The love attitudes scale: Short form. Journal of Social and Personal Relationships, 15, 147-159. doi:10.1177/0265407598152001

Hendrick, S., \& Hendrick, C. (1992). Liking, loving, \& relating ( $2^{\text {nd }}$ ed.). Pacific Grove, CA: Brooks/Cole.

Jöreskog, K. G., \& Sörbom, D. (1984). LISREL 6: User's guide [Computer software]. Mooresville, IN: Scientific Software International.

Kerckhoff, A., \& Davis, K. (1962). Value consensus and need complementarity in mate selection. American Sociological Review, 27, 295-303. doi:10.2307/2089791

Knapp, M. (1984). Interpersonal communication and human relationships. Boston, MA: Allyn \& Bacon.

Le, B., \& Agnew, C. (2003). Commitment and its theorized determinants: A meta-analysis of the investment model. Personal Relationships, 10, 37-57. doi:10.1111/1475-6811.00035

Levinger, G. (1974). A three-level approach to attraction: Toward an understanding of pair relatedness. In T. Huston (Ed.), Foundations of interpersonal attraction (pp. 100-120). New York: Academic Press.

Levinger, G., \& Snoek, J. D. (1972). Attraction in relationship: A new look at interpersonal attraction. Morristown, NJ: General Learning Press.

Lewis, R. (1972). A longitudinal test of a developmental framework for premarital dyadic formation. Journal of Marriage and the Family, 35, 16-26. doi:10.2307/351092

Miller, R., Perlman, D., \& Brehm, S. (2007). Intimate relationships ( $4^{\text {th }}$ ed.). New York: McGraw-Hill.

Montoya, R., Horton, R., \& Kirchner, J. (2008). Is actual similarity necessary for attraction? A meta-analysis of actual and perceived similarity. Journal of Social and Personal Relationships, 25, 889-922. doi:10.1177/0265407508096700

Moser, G. (1994). Les relations interpersonnelles. Paris, France: Presses Universitaires de France.

Murstein, B. (1970). Stimulus-Value-Role: A theory of marital choice. Journal of Marriage and the Family, 32, 465-481. doi: $10.2307 / 350113$

Muthén, L., \& Muthén, B. (2010). Mplus user's guide ( $6^{\text {th }}$ ed.) [Computer software]. Los Angeles, CA: Author.

Regan, P., Kocan, E., \& Whitlock, T. (1998). Ain't love grand! A prototype analysis of the concept of romantic love. Journal of Social and Personal Relationships, 15, 411-420. doi:10.1177/0265407598153006

Reiss, I. (1960). Toward a sociology of the heterosexual love relationship. Marriage and Family Living, 22, 139-145. doi: $10.2307 / 347330$

Rodrigues, D. (2010). “Só de olhar para ti...”: O fenómeno de atracção inicial (Tese de doutorado não-publicada, Instituto Universitário de Lisboa, Lisboa, Portugal).

Rodrigues, D., \& Lopes, D. (2014). Development and validation of the Measure of Initial Attraction (MIA). International Journal of Social Psychology, 29, 532-562. doi:10.1080/02 134748.2014.981388

Rodrigues, D., Lopes, D., Alexopoulos, T., \& Goldenberg, L. (2014). When I look at you: The Unilateral Initial Attraction (UIA) phenomenon. European Journal of social Psychology. Manuscript submitted for publication.

Rubin, Z. (1970). Measurement of romantic love. Journal of Personality and Social Psychology, 16, 265-273. doi:10.1037/ h0029841 
Rusbult, C. (1980). Commitment and satisfaction in romantic associations: A test of the investment model. Journal of Experimental Social Psychology, 16, 172-186. doi:10.1016/00221031(80)90007-4

Rusbult, C. (1983). A longitudinal test of the investment model: The development (and deterioration) of satisfaction and commitment in heterosexual involvements. Journal of Personality and Social Psychology, 45, 172-186. doi:10.1037//00223514.45.1.101

Rusbult, C., \& Righetti, F. (2009). Investment model. In H. Reis \& S. Sprecher (Eds.), Encyclopedia of human relationships (pp. 927-930). Thousand Oaks, CA: Sage.

Scanzoni, J. (1979). Social exchange and behavioral interdependence. In R. Burgess \& T. Huston (Eds.), Social exchange in developing relationships (pp. 61-98). New York: Academic Press.

Simpson, J., Gangestad, S., \& Lerma, M. (1990). Perception of physical attractiveness: Mechanisms involved in the maintenance of romantic relationships. Journal of Personality and Social Psychology, 59, 1192-1201. doi:10.1037//00223514.59.6.1192

Sprecher, S., \& Felmlee, D. (2008). Insider perspectives on attraction. In S. Sprecher, A. Wenzel, \& J. Harvey (Eds.), Handbook of relationship initiation (pp. 297-314). New York: Psychology Press.

Sternberg, R. (1986). A triangular theory of love. Psychological Review, 93, 119-135. doi:10.1037//0033-295X.93.2.119 